\title{
Development of a new instrument for measurement of high temperature mechanical properties of resin-bonded sand
}

\author{
${ }^{*}$ Peng Wan', Yuan-cai Li ${ }^{1}$, Hong-jiang Ling ${ }^{1}$, Wen-qing Wang ${ }^{1}$, He-yi Zhi ${ }^{2}$ and Jiang Xue ${ }^{2}$ \\ 1. State Key Laboratory of Materials Processing and Die \& Mould Technology, Huazhong University of Science \& Technology, Wuhan 430074, \\ China \\ 2. Wuxi Sanfeng Instrument Equipment Co. Ltd., Wuxi 214151, Jiangshu, China
}

\begin{abstract}
The mechanical properties of resin-bonded sand mixtures at high temperatures significantly affect the quality of casting. However, the existing instruments for high-temperature performances testing mainly focus on inorganic binder-bonded sands no matter the test items or the atmospheric protection, while the instrumentss specially designed for resin-bonded sand are not yet available. A new instrument for testing the hightemperature performance of resin sand was designed including the confirmation of the testing parameters, loading, measurement and control systems, and the design of the frame shape and heating furnace. This instrument can test the compressive strength, heat tolerance time and restraining load of phenol-formaldehyde resin coated sand, self-hardened furan resin sand, and trimethylamine (TEA)-based resin bonded sand at high temperatures. The developed instrument has a high accuracy offering smaller than $0.3 \%$ deviation at a full scale in the measurement of the high temperature compressive strength and the restraining load over the range of 0-6.8 MPa and 0-2,000 N, respectively. The high temperature heat tolerance time range is $0-300 \mathrm{~s}$ and its measurement accuracy is $\pm 1 \mathrm{~s}$.
\end{abstract}

Key words: resin-bonded sand; high temperature mechanical properties; high temperature compressive strength; high temperature heat tolerance time; restraining load

CLC numbers: TG221 ${ }^{+} 1 \quad$ Document code: A Article ID: 1672-6421(2017)04-286-06

$\mathrm{T}$ he mechanical properties of sand mixtures at high temperatures are directly related to the internal and surface qualities of castings ${ }^{[1]}$. With more strict requirements on casting quality being imposed, resin bonded sand hardened by various methods has been increasingly used in the last 30 years. The research and development in such field mainly focused on the properties of resin-bonded sand at room temperature. Except for the detection of gas evolution, other hightemperature properties have rarely been studied ${ }^{[2-5]}$. The main reason was that, in China, the available instruments for measuring the high-temperature mechanical properties of sand mixtures were not designed specifically for resinbonded sand ${ }^{[6]}$. The binder in a resin-bonded sand is organic matter, so various physico-chemical changes may happen when resin-bonded sand comes into contact with liquid metal. In this process, hydrocarbons will produce a reducing atmosphere which greatly differs

\footnotetext{
* Peng Wan

Male, 1988, doctoral candidate. His research mainly focuses on the high temperature performance of resin sand.

E-mail: 382663254@qq.com
}

Received: 2016-10-09; Accepted: 2017-04-06 from the oxidising atmosphere produced by other inorganic binder bonded sands including green sand and sodium silicate sand. Thus, its collapse process and fracture mechanisms are also different from the aforementioned inorganic binder bonded sands ${ }^{[7]}$. Therefore, it is necessary to develop an instrument that can measure the high-temperature mechanical properties of resin-bonded sand.

\section{Test parameters and design requirements}

\subsection{Test parameters}

Currently, the high-temperature performances of resinbonded sand are mainly evaluated according to the testing standards for common sand mixtures, and the testing parameters include: compressive strength, retained strength, thermal expansion, retaining load, shock load expansion, and thermal deformation at high temperatures ${ }^{[8]}$, as well as the high-temperature heat tolerance time.

High-temperature compressive strength $(\mathrm{MPa})$ is the instant strength of sand mixtures kept at high 
temperature for a period of time. The restraining load (N) is the load required to maintain the specimen length at high temperature. The high-temperature heat tolerance time (s) denotes the time during which resin-bonded sand retains its original strength. Among these test parameters, the hightemperature compressive strength is one of the key parameters reflecting the strength properties of the sand mixture at high temperatures. The restraining load reflects the sand's ability to accommodate thermal expansion. Resin-bonded sand undergoes many physico-chemical changes when it contacts with molten metal. This differs from other inorganic binder bonded sands such as green sand and sodium silicate sand. It is clear that the measurement of high-temperature heat tolerance time is important. Therefore, the compressive strength, heat tolerance time, and restraining load were selected as the key measurement parameters for the testing of high-temperature mechanical properties of resin-bonded sand.

\subsection{Design requirements for the new instrument}

Based on the instruments available ${ }^{[6]}$, the design of this new instrument for high-temperature mechanical properties measurement of resin-bonded sand mixtures needs to provide improvement in the following aspects:

(1) Most traditional instruments for moulding materials are large and expensive. For example, the size of the No.785 high-temperature performance tester produced by the Dietert Company (USA) is approximately $838 \times 533 \times 1,956 \mathrm{~mm}$; and that of the SQW-A high-temperature strength tester is approximately $720 \times 500 \times 1,644 \mathrm{~mm}$. The new tester should be as compact as possible.

(2) The resin-bonded sand is serviced under a reducing atmosphere, while the results measured under an oxidizing atmosphere are quite different ${ }^{[9]}$. Most of the instruments cannot adjust the atmosphere. Therefore, they cannot reflect the real properties of resin-bonded sand at high temperatures. The new instrument should be able to produce a reducing atmosphere.

(3) As the existing instruments cannot reflect casting defects, current test items subject to assessment of the high-temperature properties are ineffectual in analyzing or preventing casting defects. For example, high-temperature heat tolerance time is an important performance parameter for resin-bonded sand, but most of the instruments cannot measure it.

The new instrument should be able to measure hightemperature heat tolerance time. It requires the load remains constant in the process of measuring. Servo motor can be used to meet such a requirement.

(4) Samples for the high-temperature performance testing of sand mixtures tend to be either too large or too small ${ }^{[10]}$. Large samples are difficult to be heated through before their surfaces are damaged; while small samples are difficult to clamp. Therefore, the sample size was set at $\Phi 20 / 5 \times 30 \mathrm{~mm}$ for all experiments in this study.

\section{Instrument design}

The functional modules of the instrument are shown in Fig. 1. It comprises a frame, a furnace, a loading system, a measurement system and a control system.

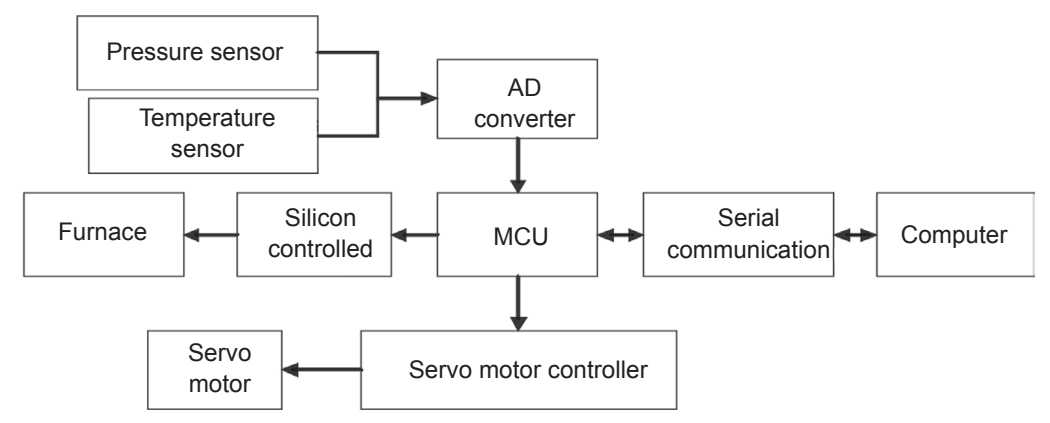

Fig. 1: Functional modules of new instrument

\subsection{Design of frame}

The structure of the frame (dimension: $400 \times 500 \times 1,264 \mathrm{~mm}$ ) is shown in Fig. 2. The designed instrument covers an area of less than half of similar instruments with about a $25 \%$ lower height.

\subsection{Design of furnace}

A threaded silicon carbide rod of $\Phi 40 / 30 \times 300 \mathrm{~mm}$ was used for heating purpose, and polycrystalline mullite fibre with the heat resisting temperature of $1,350{ }^{\circ} \mathrm{C}$, was selected as the furnace chamber lining material.

To ensure the heating effect of the furnace, the thermal equilibrium of the furnace was checked. The outside diameter, inside diameter, and height of the furnace were $d_{1}$, $d_{2}$, and $L$, respectively: assuming that the heating temperature $t_{2}$ was $1,350{ }^{\circ} \mathrm{C}$, the outer wall temperature of the furnace $t_{1}$ was $30{ }^{\circ} \mathrm{C}$. The average thermal conductivity $\lambda$ value of $0.18 \mathrm{~W} \cdot \mathrm{m}^{-1} \cdot \mathrm{K}^{-1}$ was taken, and the rated power of the furnace is $800 \mathrm{~W}$, then

The side thermal resistance $R_{\mathrm{s}}=\frac{\ln \frac{d_{1}}{d_{2}}}{2 \pi \lambda L}=6.1 \mathrm{~K} \cdot \mathrm{W}^{-1}$

The end-face thermal resistance $R_{\mathrm{e}}=\frac{L}{2 \pi \lambda d_{2}^{2}}=279 \mathrm{~K} \cdot \mathrm{W}^{-1}$

The heat dissipated power

$$
Q=\frac{t_{2}-t_{1}}{R_{\mathrm{s}}}+2 \frac{t_{2}-t_{1}}{R_{\mathrm{e}}}=225 \mathrm{~W}
$$




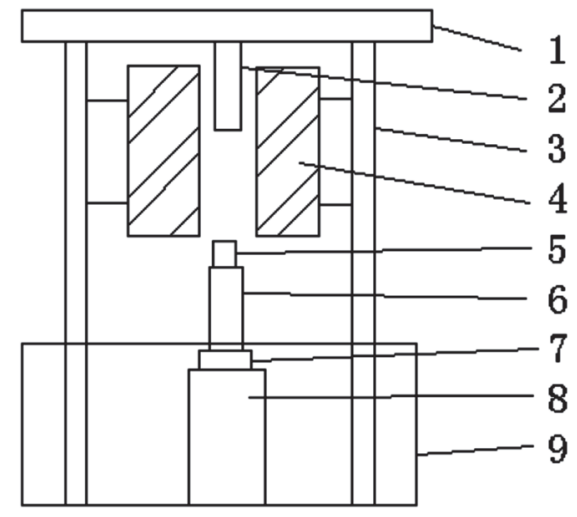

1 - beam, 2 - alumina rod, 3 - columns, 4 - furnace 5 - specimen, 6 - alumina rod, 7 - pressure sensor 8 - servo motor, 9 - box

(a)

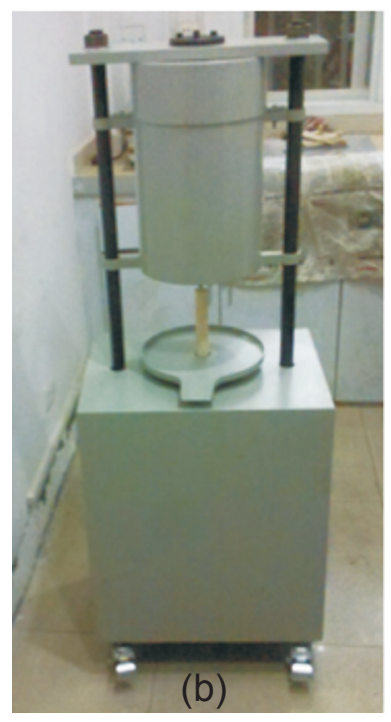

Fig. 2: Frame structure of instrument

Safety factor $\mathrm{n}=\frac{800 \mathrm{~W}}{225 \mathrm{~W}}=3.55$ (safety factor should be greater than 1.2)

According to the calculated results, the heat dissipation power of the furnace was far smaller than the applied power, so it meets the design requirements. Experiments showed that it took $10 \mathrm{~min}$ to heat up from room temperature to $1,000^{\circ} \mathrm{C}$.

\subsection{Design of loading, measurement, and control systems}

An electrical loading system equipped with a JX20-010 servomotor was used: the maximum applicable load and maximum cross-head rate of displacement were $6,400 \mathrm{~N}$ and $100 \mathrm{~mm} \bullet \mathrm{s}^{-1}$, respectively.

The measuring system was mainly used to measure the temperature and pressure within ranges of $0-1,350{ }^{\circ} \mathrm{C}$ and $0-2,000 \mathrm{~N}$, respectively. The $\mathrm{S}$ type thermocouple was selected as the temperature sensor. The environmental temperature was measured using a TMP121 digital temperature sensor to compensate for the temperature change during testing. An RSS01-type pressure sensor was used as the pressure sensor.

For the control system, a C8051F350 Micro Control Unit (MCU) ${ }^{[11]}$ was used as the main control chip, while TRIAC and the servo-motor controller were used to control the temperature and movement, respectively.

\subsection{Design of the software system}

Visual C++ 2012 was used for programming: software interfaces include a main interface showing the heating process and three testing parameter sub-interfaces. The program can control the heating temperature, automatically carry out a test, and report the test results thereafter.

\section{Adjustment and application}

\subsection{Reducing atmosphere}

The easiest way to produce a reducing atmosphere is to add a lid above the furnace ${ }^{[8]}$. This method is closer to the actual situation during casting compared with that produced by blowing inert gas. Therefore, the furnace was fixed and then sealed with a lid to produce reducing atmosphere. Before testing, several samples were heated to consume the oxygen in the furnace chamber, and thus produce a reducing atmosphere.

The following experiment was performed to determine when a reducing atmosphere can be generated in the furnace. At first, the furnace was sealed with the lid, then five specimens were put into the furnace in turn after the instrument has been booted and pre-heated. Then a small porthole in the lid was opened to extract the gas above the sample with a syringe for gas chromatographic analysis. The volume fractions of its main components are shown in Table 1. The lid was then removed and the instrument was turned off. The repeat tests indicated that the volume fractions of its main components are similar to those in Table 1. It is observed that a small amount of carbon monoxide was produced and the oxygen was consumed (a little oxygen was possibly present in the suction catheter of the syringe) if the lid is sealed. It can be judged that the furnace chamber provided a reducing atmosphere after continuous measurement of five samples as the furnace was sealed.

Table 1: Gas chromatographic analysis

\begin{tabular}{ccc} 
Type of gas & $\begin{array}{c}\text { Volume fraction } \\
\text { (lid sealed, \%) }\end{array}$ & $\begin{array}{c}\text { Volume fraction } \\
\text { (lid removed, \%) }\end{array}$ \\
$\mathrm{O}_{2}$ & 3.29 & 9.91 \\
$\mathrm{~N}_{2}$ & 81.04 & 79.89 \\
$\mathrm{CO}$ & 1.25 & 0 \\
$\mathrm{CO}_{2}$ & 14.42 & 10.2 \\
\hline
\end{tabular}

The coating sand for cast iron in a company was used to prepare samples. The samples were hardened at $225{ }^{\circ} \mathrm{C}$ for 2 min and kept in a dessiccator for $24 \mathrm{~h}$ at room temperature. Finally, high-temperature properties (reducing gas evolution and burning) of resin bonded sand were tested at $1,000{ }^{\circ} \mathrm{C}$, so the samples were kept at $1,000{ }^{\circ} \mathrm{C}$ for $1 \mathrm{~min}$ and then their high- 
temperature compressive strengths were measured one-by-one. High-temperature compressive strengths for two different cases are shown in Table 2.

It can be found from Table 2 that if the furnace was sealed and preheated using three to five samples, a reducing atmosphere was generated, leading to the reduction of the rate of decomposition of the resin and increase in the high temperature compressive strength. If the lid was removed, no reducing atmosphere could be produced, so the high temperature compressive strength changed little.

\subsection{Measurement accuracy}

The measurement accuracy was greatly improved after adjustment. The variation coefficient of the measured values decreased to less than $10 \%$. Therefore, the measurement results
Table 2: High-temperature compressive strength of different samples (MPa)

\begin{tabular}{ccc} 
Sample no. & High temperature compressive strength \\
& Lid sealed & Lid removed \\
1 & 0.10 & 0.11 \\
2 & 0.14 & 0.13 \\
3 & 0.18 & 0.14 \\
4 & 0.19 & 0.13 \\
5 & 0.19 & 0.12 \\
\hline
\end{tabular}

were deemed reliable. The technological parameters of the instrument are listed in Table 3.

Table 3: Technological parameters of developed instrument

\begin{tabular}{lc}
\multicolumn{1}{c}{ Parameters } & Values \\
Measuring range of high temperature compressive strength/Precision (MPa) & $0-6.8 / 0.02$ \\
Measuring range of restraining load/Precision (N) & $0-2,000 / 6$ \\
Measuring range of high temperature heat tolerance time/Precision (s) & $0-300 / 1$ \\
Maximum temperature $\left({ }^{\circ} \mathrm{C}\right)$ & 1,350 \\
Maximum loading force $(\mathrm{N})$ & 2,000 \\
Sample size (mm) & $\Phi 20 / 5 \times 30$ \\
Instrument dimensions $(\mathrm{mm})$ & $400 \times 500 \times 1264$ \\
Power and voltage & $220 \mathrm{~V}, 50 \mathrm{~Hz}$ \\
Attachment & a computer
\end{tabular}

\section{High temperature performance comparison of different resin-bonded sands}

The high-temperature performance of different resinbonded sands was measured, as shown in Table 4 and Figs. 3 to 8 , where $1 \#, 2 \#, 3 \#$, 4\#, and 5\# represent coating sand for cast iron, special coated sand, ceramsite resin-coated sand, self-hardened furan resin sand for cast iron (Dalin standard sand as the base sand, with 1.5\% resin), and a TEA-based resin-bonded sand (with $1.5 \%$ resin), respectively. The $6 \#, 7 \#, 8 \#$, and $9 \#$ denote selfhardened furan resin sand for cast iron (Dalin standard sand as the base sand) with $1 \%, 1.25 \%, 1.75 \%$, and $2 \%$ resin, respectively. The sands used in the present experiment were all commercially available coated sand and preserved at $225{ }^{\circ} \mathrm{C}$ for $2 \mathrm{~min}$. The added amount of curing agent was $60 \mathrm{wt} . \%$ of resin. For the TEAbased resin-bonded sand, the proportion of components I (benzylic ether phenolic resin) and II (polyisocyanate) was $1: 1$. The sample size was $\Phi 20 / 5 \times 30 \mathrm{~mm}$. The high temperature performance was tested $24 \mathrm{~h}$ after the
Table 4: Comparison of high-temperature performance of different resin-bonded sands

\begin{tabular}{cccc}
$\begin{array}{c}\text { Types of resin } \\
\text { sand }\end{array}$ & $\begin{array}{c}\text { High temperature } \\
\text { compressive } \\
\text { strength (MPa) }\end{array}$ & $\begin{array}{c}\text { High temperature } \\
\text { heat tolerance } \\
\text { time (s) }\end{array}$ & $\begin{array}{c}\text { Restraining } \\
\text { load (N) }\end{array}$ \\
\hline 1\# & 0.20 & 222 & 29.2 \\
$2 \#$ & 0.37 & 185 & 20.9 \\
3\# & 0.26 & 76 & 16.8 \\
4\# & 0.12 & 127 & 27.4 \\
5\# & 0.08 & 63 & 23.3 \\
6\# & 0.09 & 90 & 14.4 \\
7\# & 0.11 & 100 & 21.5 \\
8\# & 0.13 & 149 & 28.6 \\
9\# & 0.13 & 163 & 27.9 \\
\hline
\end{tabular}

sample was hardened. The high temperature compressive strength was measured at $1,000{ }^{\circ} \mathrm{C}$ and its holding time was $1 \mathrm{~min}$. The hightemperature heat tolerance time was measured at $1,000{ }^{\circ} \mathrm{C}$ and its load pressure was $0.1 \mathrm{MPa}$. The restraining load was measured at $1,000{ }^{\circ} \mathrm{C}$ 


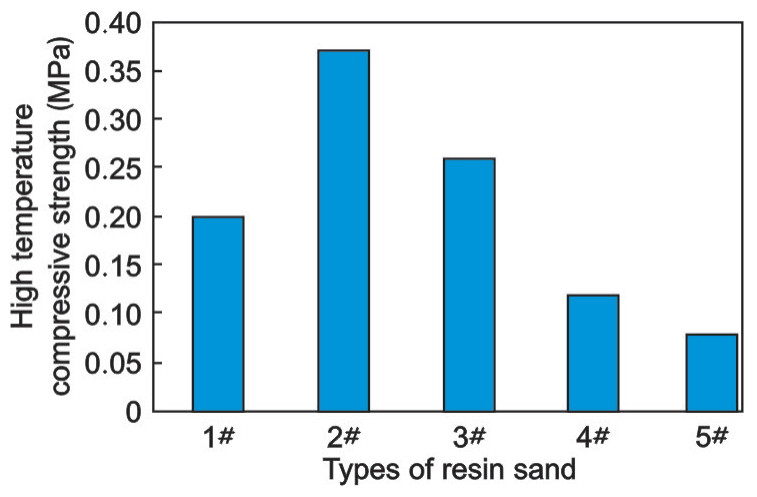

Fig. 3: High-temperature compressive strengths of different resin-bonded sands

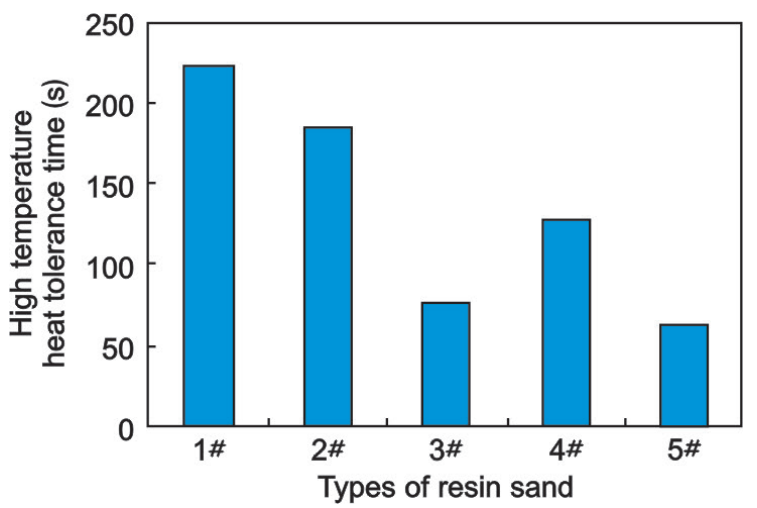

Fig. 4: High-temperature heat tolerance times of different resin-bonded sands

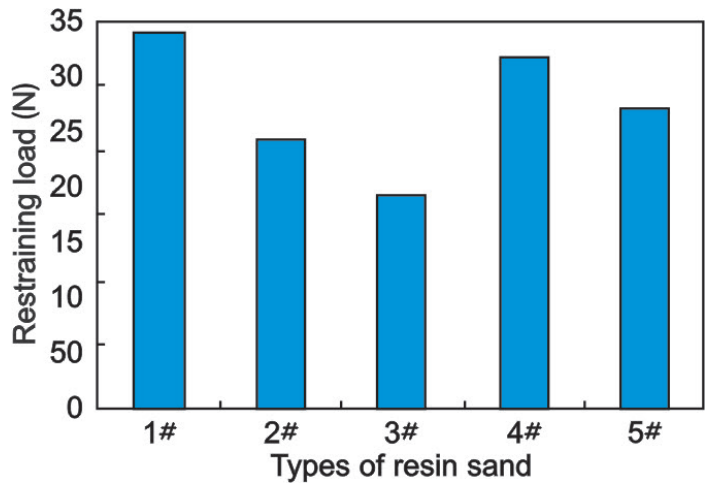

Fig. 5: Restraining loads of different resinbonded sands

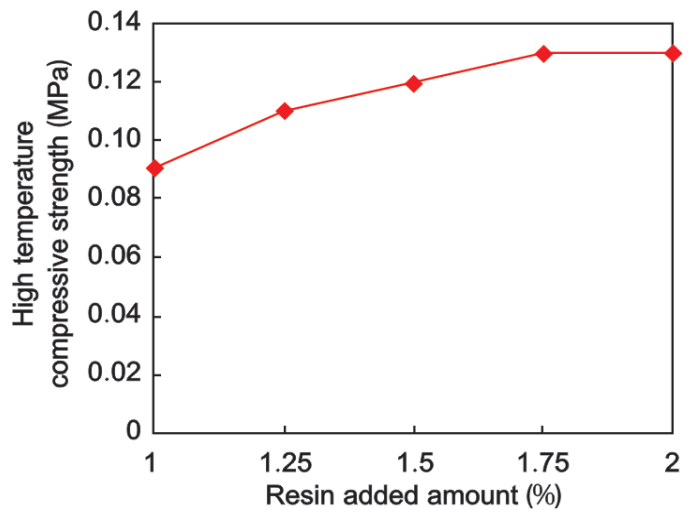

Fig. 6: High-temperature compressive strengths with different amounts of resin

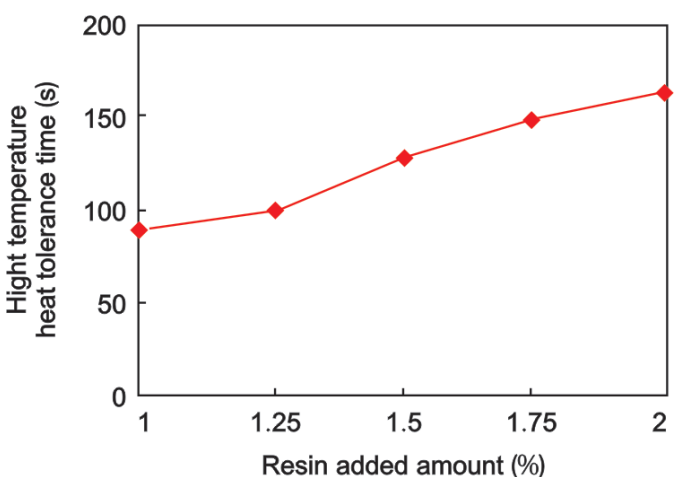

Fig. 7: High-temperature heat tolerance times with different amounts of resin

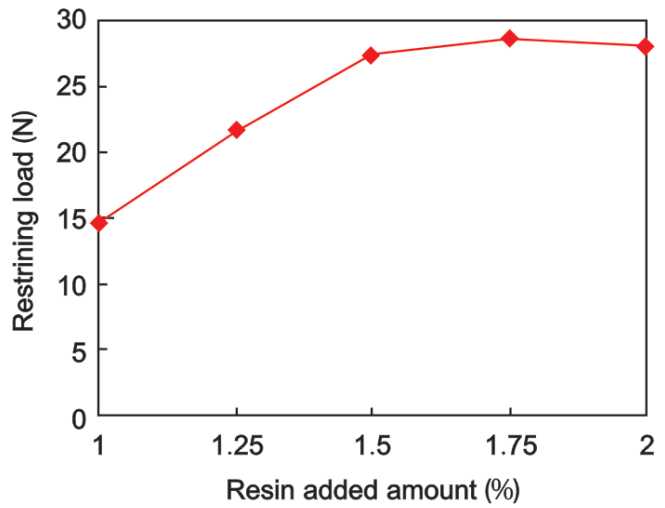

Fig. 8: Restraining load with different amounts of resin

and its load pressure was $10 \mathrm{~N}$. All the items were measured five times, from which the highest and lowest values were removed before averaging to obtain the final measured result.

As shown in Figs. 3 to 5, the phenol-formaldehyde resincoated sand had a higher high temperature compressive strength and longer high temperature heat tolerance than the TEAbased resin-bonded sand and the self-hardened furan resin sand, and its restraining load was also higher. This was caused by its higher room temperature strength, for which more binding bridges with higher strength and longer duration remained at higher temperatures. Ceramsite resin-coated sand had the lowest restraining load, which was related to its special nature of the raw sand. As the sand grains are round, it exhibited a small thermal expansion. Special coated sand had the highest strength, which was consistent with its good high temperature performance in general use. Therefore, the instrument could reflect the high temperature performance differences between different resin-bonded sands.

Figures 6 through 8 show that the high temperature compressive strength, high temperature heat tolerance time, and restraining load gradually increase with the increasing resin content. This is because, with the increasing resin content, more residual resin is left at high temperatures, thus improving its high temperature compressive strength and high temperature heat tolerance time, hindering the free expansion of sand grains at high temperatures, and thus, increasing its restricted thermal expansion force. The results can, therefore, reflect the high temperature performance of different resin-bonded sands. 
The coefficients of variation of the measured values are less than $10 \%$. Therefore, the measurement results can be considered accurate and reliable.

\section{Conclusions}

(1) The newly developed instrument can test the high temperature compressive strength, high temperature heat tolerance time, and restraining load of phenol-formaldehyde resin-coated sand, self-hardened furan resin sand, and TEAbased resin bonded sand.

(2) The instrument delivers high accuracy: the hightemperature compressive strength and the restraining load can be measured over ranges of $0-6.8 \mathrm{MPa}$ and $0-2,000 \mathrm{~N}$ with the measurement accuracy better than $0.3 \%$ at a full scale. The high temperature heat tolerance time range is $0-300 \mathrm{~s}$ and its measurement accuracy is $\pm 1 \mathrm{~s}$.

(3) The test results can reflect the high temperature performance differences between various resin-bonded sands, and therefore, reflect the high temperature performance of different resin-bonded sands.

\section{References}

[1] Dai Xuqi, Wang Wenqing. The present situation and development trend of moulding sand quality detection technology at home and abroad. Ductile Iron, 1990(3): 1-4. (In Chinese)
[2] GB/T 2684-2009 Test Methods for Foundry Sands and Molding Mixtures. Beijing: Standards Press of China, 2009. (In Chinese)

[3] JB/T 3828-1999 Hot Box resin for Foundry. Beijing: Standards Press of China, 1999. (In Chinese)

[4] JB/T 7526-2008 Self-set furan resin for foundry. Beijing: Standards Press of China, 2008. (In Chinese)

[5] JB/T 8583-2008 Resin coated sand for foundry. Beijing: Standards Press of China, 2008. (In Chinese)

[6] Wan Peng,Li Yuancai, Ling Hongjiang, et al. Present status and development of molding sand high temperature test and its apparatus. Foundry Equipment and Technology, 2014(1): 1-7, 12. (In Chinese)

[7] Stanisaw M. Dobosz, Petr Jelinek, Katarzyna Major-Gabry. Development tendencies of moulding and core sands. China Foundry, 2011(04): 438-446.

[8] Des Plaines Illinois. Foundry sand handbook. The American Foundrymen Society, 1963.

[9] Shao Jingcheng, Wu Min, Ai Guo, et al. Effects of Oxidants on Collapsibility of Resin Bonded Sand. Foundry, 2011(1): 70-72. (In Chinese)

[10] Zhou Zaili, Shi Xiaoyang, Zhang Xuguo, et al. Determination of the High Temperature Properties of Coated Sand. Foundry Technology, 2011(8): 1064-1066. (In Chinese)

[11] Wang Fang, Ling Hongjing. The multi-point temperature measurement system based on Proteus simulation. Computer Programming Skills \& Maintenance, 2014, (7): 85-88. (In Chinese) 